\title{
UNA PRESENCIA CONSTANTE: LOS ESCLAVOS SARRACENOS EN VALENCIA (SIGLOS XIII-XVI)
}

\author{
Francisco Javier Marzal Palacios
}

La presencia de esclavos sarracenos se presenta como una de las cuestiones más destacadas de la esclavitud valenciana, tanto por su número como, de forma especial, por su continuidad. Frente a lo que ocurre con otros colectivos esclavos, caso de los orientales, balcánicos o subsaharianos, por citar sólo a los más relevantes, los sarracenos van a estar presentes a lo largo de todo el período bajomedieval, pudiéndoseles encontrar igualmente en la Valencia moderna. El objetivo de este trabajo no es tanto el poner de manifiesto esa imp ortancia del elemento sarraceno en el conjunto de la esclavitud valenciana, algo ya suficientemente conocido, como señalar los rasgos definitorios de esa presencia esclava, primero repasando, a través de la bibliografía existente sobre el tema, los principales aspectos de la misma entre los siglos XIII y XVI y posteriormente centrándonos, con una relativa profundidad, en el estudio de un período reducido dentro de esa cronología plurisecular, concretamente el comprendido entre los años 1409 y 1425, lo que haremos a partir de nuestra propia investigación, siendo cuatro los temas a abordar, el ap rovisionamiento, la caracterización del grupo, el mercado y las vías hacia la libertad. Previamente, y puesto que la presencia de esclavos sarracenos no era un fenómeno exclusivo del reino de Valencia, al tener ésta lugar, con mayor o menor intensidad, en todo el espacio del Mediterráneo occidental cristiano, señalaremos de forma breve y también en base a la bibliografía existente los aspectos más relevantes de esa presencia esclava sarracena en ciudades como Génova, Palermo, Barcelona, Palma de Mallorca o Marsella.

\section{LOS ESCLAVOS SARRACENOS EN EL OCCIDENTE MEDITERRÁNEO BAJOMEDIEVAL}

Comenzando por uno de los centros esclavistas más importantes del Mediterráneo occidental, la ciudad de Génova, allí los esclavos sarracenos van a pasar de ser la gran may oría a tener una presencia simplemente testimonial, para recup erar con posterioridad su importancia. Así, y como señala Michel Balard, cerca del 75\% de los esclavos genoveses entre 1239 y 1274 eran sarracenos, en su mayoría ibéricos, unos sarracenos que a partir de 1275, con el inicio de la trata desde el Mar Negro, con base sobre todo en la colonia genovesa de Caffa, en Crimea, y que, especialmente desde inicios de la segunda mitad del siglo XIV, conducía hasta la metrópoli 
a centenares de esclavos orientales, van a ver disminuir de forma drástica su peso en el conjunto de la población esclava genovesa. En el último cuarto del siglo XIII ya suponen únicamente un tercio de los esclavos, porcentaje que progresivamente se va a ir reduciendo, pasando de un $18 \%$ entre 1300 y 1320 a un 0,5\% entre 1381 y 1408 . La tendencia que se aprecia durante la may or parte del siglo XV, período estudiado por Domenico Gioffrè, es la práctica ausencia de esclavos sarracenos, algo que sólo se va a romp er en su último tercio, cuando éstos, que se van a constituir en el colectivo más numeroso de entre los que componen en esas décadas la clase servil en la capital ligur, van a actuar de recambio, junto a los balcánicos, de los esclavos orientales, unos esclavos orientales que tras las conquistas otomanas de Constantinopla en 1453 y Caffa en 1475 dejan prácticamente de llegar al Mediterráneo occidental ${ }^{1}$.

El proceso que acabamos de señalar para Génova no constituye la norma, constituye la excepción. En la gran may oría de ciudades del occidente mediterráneo los esclavos sarracenos no desaparecen ante la llegada de esclavos de otras procedencias, ya orientales o balcánicos ya subsaharianos, sino que permanecen en mayor o menor grado,formando entre todos, y con la presencia igualmente, aunque en menor cantidad y no en todos los sitios, de elementos canarios, turcos o sardos, un colectivo esclavo, en cuanto a sus orígenes, notablemente heterogéneo, diverso. Es algo que se aprecia perfectamente en Palermo. Henri Bresc divide el período 1280-1460, por lo que a la tipología de esclavos se refiere, en cinco grandes ciclos. El primero, que comprende los años 1280-1310, es el del esclavo sarraceno; el segundo, años 1310-1359, el del esclavo griego; el tercero, 1360-1399, el del esclavo tártaro; el cuarto, 1400-1439, se caracteriza por un equilibrio entre las diversas procedencias; y el quinto y último, 1440-1460, es el ciclo del esclavo negro. Lo destacable es que a lo largo de todos esos años, salvo en el período 1360-1399, cuando la marea tártara inunda los mercados occidentales, la presencia sarracena es importante, may oritaria entre los siglos XIII y XIV y significativa en el resto de la cronología ${ }^{2}$.

1. M. BALARD, “Remarques sur les esclaves à Gênes dans la seconde moitié du XIIIe siècle”, Mélanges d'Archéologie et d'Histoire publiés par l'École Française de Rome, (1968), pp. 627-680, especialmente pp. 643-649; ÍDEM, La Romanie génoise (XIIe - début du XVe siècle), 2 vols., París - Roma, 1978, vol. 2, pp. 785-833, especialmente pp. 788-790; R. DELORT, “Quelques précisions sur le commerce des esclaves à Gênes vers la fin du XIVe siècle”, Mélanges d'Archéologie et d'Histoire de l'École Française de Rome, (1966), pp. 215-250, especialmente pp. 218-222; D. GIOFFRÈ, Il mercato degli schiavi a Genova nel secolo XV, Génova, 1971, especialmente pp. 27-33; Ch. VERLINDEN, L'escla vage dans l'Europe médiévale, vol. II, Italie - Colonies italiennes du Levant - Levant latin - Empire byzantin, Gante, 1977, pp. 427-549, especialmente pp. 450-451, pp. 474-475 y pp. 487-489.

2. H. BReSC, Un monde méditerranéen. Économie et société en Sicile, 1300-1450, 2 vols., Pal ermo-Ro ma, 1986, vol. 2, pp. 439-475, especialmente pp. 439-454 para Palermo y pp. 454-462 para otras localidades sicilianas; Ch. VERLinden, L'esclavage..., vol. II, cit., pp. 138-282, especialmente pp. 138-167 y pp. 227-229. 
En Mallorca la esclavitud sarracena muestra igualmente una notable importancia y continuidad. La conquista cristiana comportó, como ha señalado Ricard Soto, la esclavización de gran parte de la población musulmana de la isla. Paralelamente a la presencia de esos esclavos locales, y especialmente tras su agotamiento, se produjo la llegada de esclavos sarracenos extranjeros, norteafricanos y granadinos, que a lo largo del siglo XIV compartieron su triste destino con griegos, en los dos cuartos centrales de la centuria sobre todo, sardos y tártaros, estos dos colectivos llegados, y en número significativo, en la segunda mitad del siglo. Cuando más datos tenemos para calibrar esa importancia del elemento sarraceno es en la última centuria medieval, en su primera mitad a través de las referencias aportadas por Pierre Macaire y en su segunda gracias al trabajo sobre la esclavitud en Mallorca de Onofre Vaquer, con preciosas y muy completas informaciones sobre el origen de los esclavos que se encuentran en la mayor de las islas Baleares, sobre todo en su capital. Si los sarracenos son un colectivo fundamental en la primera mitad, por debajo de los orientales pero claramente por encima de balcánicos, sardos o subsaharianos, lo que ocurre en la segunda mitad es que los sarracenos alcanzan la primacía dentro del colectivo esclavo mallorquín, aunque compartiendo protagonismo con los subsaharianos. En un contexto de práctica desaparición de los esclavos orientales, que pasan de ser el 81\% del total de esclavos objeto de transacción en Mallorca entre 1448 y 1457 a p oco más del $8 \%$ entre 1478 y 1499, los sarracenos ven multiplicarse su peso relativo por cuatro, pasando de ser el $10 \%$ del total entre 1448 y 1457 a casi un $41 \%$ entre 1478 y $1499^{3}$.

En otra de las grandes ciudades del occidente mediterráneo, Barcelona, la esclavitud sarracena también conoce una evolución similar, siempre en términos generales, a la señalada para Palermo o Palma de Mallorca. Los sarracenos son prácticamente los únicos esclavos presentes en la ciudad hasta que a finales del primer tercio del siglo XIV hagan su ap arición los griegos, como se aprecia en el trabajo de Carme Batlle, que centra su atención en el período que envuelve el año 1300. Para el siglo XIV la presencia esclava sarracena está magníficamente documentada gracias a Josep Hernando, quien ha realizado un vaciado sistemático y exhaustivo de todos los protocolos o fuentes notariales de los diferentes archivos barceloneses, trabajo ingente que ha puesto a su alcance 1058 documentos o instrumentos notariales que, directa 0

3. R. Soto I Company, “La situació dels andalusins (musulmans i batejats) a Mallorca després de la conquesta catalana de 1230", Mélanges de la Casa de Velázquez. Antiquité - Moyen Âge, XXX - 1 (1994), pp. 167-206; J. SAStRe Moll, “Musulmanes en Mallorca, en la primera mitad del siglo XIV”, Bolletí de la Societat Arqueològica Lul liana, 48 (1992), pp. 25-50; M. PujoL, “ L’ esclavitud en el Regne de Mallorca durant el govern del Rei Martí I, 1396-1410, Bolletí de la Societat Arqueològica Lul liana, 52 (1996), pp. 129-140, especialmente pp. 131-133; P. MACAIRE, Majorque et le commerce international (1400-1450 environ), Lille, 1986, pp. 117-138, especialmente pp. 117-121; O. VAQUER BENNÀssAR, L'esclavitud a Mallorca. 1448-1500, Palma de Mallorca, 1997, especialmente pp. 9-16. 
indirectamente, hacen referencia a esclavos sarracenos. Son cerca de 1000 los esclavos sarracenos recogidos, lo que da muestra de su peso en el conjunto de la población esclava barcelonesa, aunque conviene señalar que el mismo se vería limitado a lo largo de la segunda mitad de ese siglo XIV y durante la primera mitad del XV, cuando la presencia de esclavos orientales, balcánicos o sardos se encontrase en su momento álgido. Así, María Teresa Ferrer recoge, a través de los registros del notario Joan Nadal, 201 compraventas de esclavos para finales de la década de 1380, de las que sólo 12 hacen referencia a esclavos sarracenos, en clara minoría frente a orientales, sobre todo tártaros, y balcánicos, en especial albaneses. En cualquier caso, un trabajo de mayor alcance cronológico, aunque muy poco exhaustivo, como es el realizado por Dimes Sancho, que abarca el período 1390-1509, nos sitúa ante dos hechos muy claros, como son, por un lado, la constante presencia de los esclavos sarracenos en Barcelona, aun en los momentos en los que con may or intensidad tiene lugar la llegada de esclavos de otras procedencias, y, por otro, la gran importancia de la esclavitud sarracena a fines del siglo XV e inicios del XVI, años en los que ya no llegan esclavos orientales, balcánicos o sardos y en los que, junto a los subsaharianos, los esclavos norteafricanos y granadinos van a constituir la gran may oría, por no decir la totalidad, del colectivo esclavo presente en Barcelona ${ }^{4}$.

Por lo que respecta a la Francia mediterránea, en especial Provenza y de forma señalada su capital, Marsella, tanto Charles Verlinden hace ya algunas décadas y para el conjunto de los siglos bajomedievales, como Philippe Bernardi, recientemente y para los siglos XIV y XV, han puesto de manifiesto la presencia esclava sarracena, hegemónica en el siglo XIII, con esclavos procedentes sobre todo del espacio ibérico y balear, y junto a otros colectivos en los dos últimos siglos medievales, aunque en este caso los sarracenos son originarios de forma may oritaria del norte de África. El segundo de estos autores señala que el 59\% de los esclavos por él documentados son orientales, aunque engloba bajo este nombre a sujetos procedentes igualmente del área balcánica e incluso a turcos, por lo que podemos suponer que el resto serían esclavos sarracenos y subsaharianos. En definitiva, una presencia sarracena en Marsella que se puede catalogar como destacada, con un peso relativo especialmente importante en determinados momentos, como puedan ser el siglo XIII e inicios del XIV y, pese a que faltan estudios que

4. C. BAtLle I G Allart, “Els esclaus domèstics a Barcelona vers 13002”, en M. T. FerRer I MALlOL- J. MutgÉ I VIVEs (Eds.), De l'esclavitud a la llibertat. Esclaus i lliberts a l'Edat Mitjana, Barcelona, 2000, pp. 265-296, especialmente p.268; J. HeRnANDo I Delgado, “Els esclaus sarraïns. De l'esclavitud a la llibertat. Blancs, negres, llors i turcs”, en M. T. Ferrer I Mallol - J. Mutgé I Vives (Eds.), De l'esclavitud a la llibertat. Esclaus i lliberts a l'Edat Mitjana, Barcelona, 2000, pp. 213-244; M. T. FERRER I MALlol, “Esclaus i lliberts orientals a Barcelona. Segles XIV y XV”, en M. T. Ferrer I Mallol - J. Mutgé I Vives (Eds.), De l'esclavitud a la llibertat. Esclaus i lliberts a l'Edat Mitjana, Barcelona, 2000, pp. 167-212, especialmente pp. 188-189; D. SANCHO I MARTínEZ, “La esclavitud en Barcelona en los umbrales de la Edad Moderna”, Estudios Históricos y Documentos de los Archivos de Protocolos, VII (1979), pp. 193-270, especialmente pp. 212-214 y pp. 228-231. 
permitan corroborarlo, aunque teniendo en cuenta lo que sucedía contemporáneamente en otras ciudades del Mediterráneo occidental es lícito pensar que así fuera, las décadas finales del siglo $\mathrm{XV}^{5}$.

\section{LA ESCLAVITUD SARRACENA EN VALENCIA, SIGLOS XIII-XVI}

Como no podía ser de otro modo, es la conquista cristiana la que marca el inicio de la presencia esclava sarracena en Valencia, de la misma forma que había sucedido en Mallorca unos años antes. Pese a que las conquistas de estos dos territorios no sean comp arables en cuanto al número de musulmanes esclavizados, mucho may or en la isla, lo que no ofrece ninguna duda es que muchos musulmanes valencianos perdieron la libertad en el transcurso de la misma. En este sentido, Josep Torró indica que hoy por hoy resulta imposible medir el impact o de las esclavizaciones sobre el conjunto de la población andalusí valenciana, pero que su alcance ni mucho menos puede calificarse de anecdótico, ya que sin ninguna duda serían miles las personas afectadas. Conviene recordar además que no sólo se produjeron esclavizaciones en los años de la conquista, sino que con ocasión de las sublevaciones mudéjares también muchos musulmanes valencianos perdieron su libertad, por lo que hasta finales de la década de 1270 el reino de Valencia se presenta como un importante espacio generador de esclavos musulmanes. Como señalan Robert I. Burns y el ya citado Josep Torró, la presencia en esas décadas centrales del siglo XIII de esclavos sarracenos locales en poder de cristianos es un fenómeno destacable, unos esclavos que van a desempeñar tareas de tipo doméstico y artesanal, aunque por desgracia el conocimiento que se tiene de esa presencia es bastante limitado ${ }^{6}$.

Lo que sí sabemos es que una parte de esos musulmanes valencianos esclavizados en las décadas centrales del siglo XIII no permaneció en Valencia, sino que fue colocada en diversos mercados exteriores, fundamentalmente el catalán, el ligur y el provenzal, alimentando en gran medida las filas de una población esclava sarracena de la que, para esa parte del siglo XIII, ya señalamos su origen preferentemente ibérico. Para el caso de Barcelona, Carme Batlle ha señalado recientemente las repercusiones que tuvieron en su mercado las dos sublevaciones de los mudéjares valencianos. Ya Joaquim Miret i Sans había incluido en su trabajo sobre la esclavitud de en Cataluña la transcripción de una venta, fechada en junio de 1276, en la que un

5. Ch. Verlinden, L'esclavage dans l'Europe médiévale, vol. I, Péninsule Ibérique - France, Brujas, 1955 , pp. 748-833, especialmente pp. 748-762 y p. 798, referido al conjunto de la Francia mediterránea; Ph. BERNARDI, “Esclaves et artisanat: une main d'oeuvre étrangère dans la Provence des XIIIe - XVe siècles”, en L'étranger au Moyen Âge. Actes du XXXe congrès de la S. H. M. E. S. P., París, 2000, pp. 79-94, especialmente pp. 84-85.

6. J. TORRó I ABAD, El naixement d’una colònia. Dominació i resistència a la frontera valenciana (1238-1276), Valencia, 1999, pp. 73-79; R. I. BURNS, L'Islam sota els croats. Supervivència colonial en el segle XIII al Regne de València, 2 vols., Valencia, 1990, vol. 1 p. 95 y pp. 198-203, y vol. 2 p. 107. 
judío de Valencia, lo que nos pone sobre la pista del papel de este colectivo en la comercialización de mudéjares esclavizados, vendía a un barcelonés dos musulmanes valencianos de corta edad. Carme Batlle ofrece varios ejemplos más de adquisiciones de mudéjares valencianos por barceloneses, referidos en concreto a la segunda mitad de la década de 1270 , en los que se aprecia cómo la ciudad de Valencia actuaba, en ese contexto de sublevaciones mudéjares, de mercado de concentración y redistribución, en este caso al espacio catalán, de las presas. Otra ciudad en la que los esclavos musulmanes valencianos alcanzaron una importancia significativa en determinados momentos del siglo XIII fue Génova, tal es así que Michel Balard escoge el año 1239 como fecha de inicio de su estudio sobre la esclavitud en la capital ligur en la segunda mitad de ese siglo tanto porque a partir de ese año la documentación notarial es más abundante y continua que en décadas anteriores como, y es lo que a nosotros nos interesa, porque para él resulta de sumo interés el estudio de las consecuencias que sobre el mercado genovés tuvo la conquist a de Valencia, conquista que, como ya había indicado con anterioridad Charles Verlinden, había lanzado a los mercados mediterráneos un gran número de esclavos sarracenos. En el contexto, y a señalado anteriormente, de una may oría sarracena en el conjunto de la población esclava genovesa entre 1239 y 1274, los procedentes del reino de Valencia ocupaban un lugar destacado, unos esclavos musulmanes valencianos, originarios de localidades como Xàtiva, Cullera, Dénia o Villalonga, aunque de otros muchos sólo se indica su condición de valencianos, sin más precisiones geográficas, en cuya llegada al mercado genovés tenían mucho que ver los mercaderes de Tortosa, muy activos a este resp ecto entre 1239 y 1248, sin que pueda descartarse la adquisición de esos esclavos valencianos en origen o en otros mercados p or p arte de mercaderes genoveses. Por último, conviene tener en cuenta el papel redistribuidor que ya en estas fechas ejercía la ciudad de Génova en relación al resto de Italia, en especial hacia zonas como Campania, Sicilia y, en menor medida, Toscana, por lo que es perfectamente posible que una parte de esos esclavos musulmanes valencianos partiese desde la capital ligur con dirección a otros destinos italianos. En cuanto a Marsella, la presencia de esclavos musulmanes valencianos se exp lica, desde el punto de vista de su llegada, tanto por ser una escala en la ruta que desde Cataluña conducía esos seres privados de libertad hasta Génova, y ahí se enmarcan en buena medida las ventas efectuadas en la ciudad francesa por mercaderes de Tortosa en 1248, como, aunque posiblemente con un alcance menor, por el interés que tenían los propios habitantes de esa ciudad en hacerse en origen con la mercancía humana ofertada ${ }^{7}$.

Una vez pasados esos momentos críticos de conquista y posteriores sublevaciones mudéjares, el colectivo esclavo sarraceno presente en Valencia va a estar compuesto de forma

7. C. Batlle I Gallart, “Els esclaus domèstics...”, cit., pp. 268-271 y p. 285; J. Miret I SANS, “La esclavitud en Cataluña en los últimos tiempos de la Edad Media”, Révue Hispanique, XLI (1917), p. 15; M. BALARD, “Remarques...”, cit., p. 629, pp. 634-637 y p. 669; Ch. VerLinden, L'esclava ge..., vol. I, cit., p. 261, p. 264, pp. 266-269 y pp. 748-754, y vol. II, cit., pp. 450-456. 
may oritaria por elementos llegados del exterior, tanto del norte de África como del sultanato de Granada, aunque como señalaremos posteriormente la esclavización de musulmanes locales es un hecho que tiene lugar a lo largo de todo el período bajomedieval ${ }^{8}$. En esa llegada desde el exterior el protagonismo principal recae sobre las actividades violentas, en especial el corso, quedando el aporte a través de la trata en un plano bastante secundario. Son Rafael Cariñena y Andrés Díaz, p or un lado, y José Hinojosa, por otro, los autores que con mayor empeño se han encargado de mostrar la llegada de esclavos sarracenos a través del corso, reivindicando su carácter de principal medio de abastecimiento para el reino de Valencia, siempre referido a este tipo de esclavos, y su papel en la conformación de un mercado de esclavos local, en concreto para diferentes momentos del siglo XIV y la ciudad de Valencia los primeros y para inicios del siglo XV y la ciudad de Valencia, en una de las vertientes de su trabajo, y desde las décadas finales del siglo XIV y Alicante, en otra vertiente, el segundo, a través del cual apreciamos, por lo que a esta última cuestión se refiere, la importancia del sur del reino de Valencia como zona de esclavitud sarracena ${ }^{9}$. Respecto a la trata, no son ciertamente muchas las referencias con las que contamos que nos permitan hablar de un tráfico de sarracenos con dirección a Valencia. Éstas se centran en el siglo XIV y en los territorios con los que Valencia mantenía unas relaciones esclavistas más intensas, Baleares y Cataluña. Jaume Sastre, para finales del primer tercio, señala la salida de esclavos sarracenos, y también griegos, desde Mallorca hacia Valencia, mientras que Josep Hernando cita a Valencia como origen de diversos compradores de esclavos

8. Una muestra de esa llegada de esclavos sarracenos extranjeros la encontramos, curiosamente, en el momento en el que los mismos ya se han librado de su condición esclava, cuando, una vez recuperada la libertad, parten de Valencia con destino a sus lugares de origen o a otros territorios musulmanes, en lo que constituye el epílogo de su presencia en Valencia. Sobre esa salida, M. T. Ferrer I Mallol, “La redempció de captius a la Corona catalano-aragonesa (segle XIV)”, Anuario de Estudios Medievales, 15 (1985), pp. 285-289; R. SIXTO IGLESIAS, “Emigrantes musulmanes y cautivos norteafricanos en Valencia (1428-1433)”, en VI Simposio Internacional de Mudejarismo, Zaragoza, 1995, pp. 357-364; A. DíAz BORRÁs, “Los cautivos musulmanes redimidos en Valencia”, en G. CIPOLLONE (a cura di), La liberazione dei 'captivi' tra Cristianità e Islam. Oltre la crociata e il gihad: tolleranza e servizio umanitario, Ciudad del Vaticano, 2000, pp. 737-747.

9. R. CARIÑENA BALAGUER, “La participació corsària en la configuració del mercat d' es claus valencià a les primeries del segle XIV: Pere Erau i la subhasta de barbarescs a València l’any 1307”, en XV Congreso de Historia de la Corona de Aragón, tomo I, vol. II, Zarag oza, 1997, pp. 68-82; R. CARIÑENA BALAGUER - A. DíAz BorRÁs, “Corsaris valencians i esclaus barbarescs a les darreries del segle XIV: una subhasta d’esclaus a València el 1385", Estudis Castellonencs, 2 (1984-1985), pp. 439-456; J. HinoJosA MonTALvo, “Confesiones y ventas de cautivos en la Valencia de 1409", Ligarzas, 3 (1971), pp. 113-127; ÍDEM, “Tácticas de apresamiento de cautivos y su distribución en el mercado valenciano (1410-1434)”, Qüestions Valencianes, I (1979), pp. 5-45; ÍDEM, “La esclavitud en Alicante a fines de la Edad Media”, en Les sociétés urbaines en France Méridionale et en Péninsule Iberique au Moyen Âge, París, 1991, pp. 373-392, especialmente pp. 378-381. 
sarracenos en Barcelona. Otros trabajos nos hablan de la adquisición de esclavos por gentes de Valencia tanto en Palma de Mallorca como en Barcelona, pero sin concretar el origen de los mismos, aunque lo más probable es que la mayoría de esos esclavos tuvieran un origen oriental o balcánico, puesto que, como ya hemos señalado, el mercado valenciano se abastecía de esclavos sarracenos sobre todo a través del corso, mientras que la llegada de esclavos de otras procedencias estaba comp letamente supeditada a la actividad comercial, a la trata ${ }^{10}$.

Por lo que hace referencia a la esclavización de mudéjares, ésta va a ser siempre un factor destacado en el conjunto de la esclavitud sarracena, aunque en los siglos XIV y XV su importancia relativa sin duda fue considerablemente menor de lo que lo había sido en el siglo XIII, cuando, con ocasión de las sublevaciones mudéjares, es lícito pensar que una buena parte del colectivo esclavo sarraceno presente en Valencia era natural del propio reino. En relación con esto, se puede afirmar que el elemento mudéjar va siendo cada vez menos importante en el conjunto de la esclavitud bajomedieval valenciana en función del progresivo incremento del número de esclavos de otras procedencias, y no nos referimos sólo a sarracenos extranjeros, sino también a orientales, balcánicos, subsaharianos, sardos o canarios. En esos dos últimos siglos medievales la esclavización de mudéjares no se encuentra ligada tanto a factores “extraordinarios”, vinculados a episodios bélicos, aunque en este sentido conviene señalar la importancia de las esclavizaciones en el contexto de la guerra de los Dos Pedros, en la que muchos musulmanes valencianos perdieron la libertad a manos de ambos bandos, como a factores “ordinarios”. Esto quiere decir que los mudéjares pierden su libertad tras la comisión de algún delito, ya tenga éste connotaciones religiosas, caso del adulterio o el robo, ya connotaciones civiles o políticas, como pueda ser la emigración ilegal. Para concluir con esta cuestión, únicamente señalar que la esclavización de mudéjares le confiere una cierta especificidad a la esclavitud valenciana, ya que convierte a este territorio en un espacio generador de esclavos, y no simplemente recep tor, como pudiera ser el caso ligur, siciliano, balear o provenzal, siempre sin tener en cuenta, lógicamente, el factor nacimiento, al mismo tiemp o que se presenta como un imp ort ante elemento de difusión geográfica del fenómeno esclavista, pues esos mudéjares esclavizados van a estar repartidos por buena parte de la geografía valenciana, en ocasiones inclus o p ermaneciendo en los mismos lugares en los que

10. J. SAStRe Moll, “ Notas sobre la esclavitud en Mallorca. 'El libre de sareyns e de grecs de lany de M CCC XXX’”, Mayurqa, 21 (1985-1987), pp. 101-120; J. HeRnANDo I Delgado, “ Els esclaus sarraïn s...”, cit., p. 219; Trabajos que hacen referencia a la compra en Mallorca y Barcelona de esclavos por gentes de Valencia, P. MACAIRE, Majorque et..., cit., p. 122, para la primera mitad del siglo XV; O VAQUER BENNÀssAR, L'esclavitud a Mallorca..., cit., p. 13 y p. 69, para la segunda mitad del siglo XV; D. SANCHO I MAR tíneZ, “ L a esclavitud en Barcelona...”, cit., p. 211, para el período comprendido entre los últimos años del siglo XIV y los primeros del XVI. 
hasta entonces habían vivido como personas libres a todos los efectos ${ }^{11}$.

Llegados a la altura de finales del siglo XV la esclavitud sarracena goza en el reino de Valencia, como en el resto del occidente mediterráneo, de una magnífica salud. Gracias a los trabajos de Vicenta Cortés conocemos la llegada de esclavos a la ciudad de Valencia entre los siglos XV y XVI, mientras que para Alicante, el segundo centro esclavista del reino, en constante progresión, contamos con los trabajos de José Hinojosa. A partir de esos estudios se puede afirmar que los esclavos que en mayor número entraron en Valencia en esas décadas fueron los subsaharianos, no en vano el reino de Valencia estaba plenamente integrado en la trata de negros procedente de los espacios portugués y andaluz. Con todo, como hemos señalado, la presencia de esclavos sarracenos era importante en el territorio valenciano. En los años que marcan el tránsito de la Edad Media a la Moderna destaca la reducida llegada de esclavos procedentes de la guerra de Granada, que además lo hacen de forma tardía y a través de la intermediación castellana, y, en sentido contrario, la gran afluencia de esclavos tras las tomas de Orán y Tríp oli, no así en el caso de la de Bugía, que no tuvo una incidencia similar en la esclavitud valenciana. Estamos sin embargo ante acontecimientos extraordinarios, que rompen la continua pero por lo general no muy elevada afluencia de esclavos sarracenos, ya fuera a través del corso, ya, aunque en menor cantidad, a través de la trata, unos esclavos sarracenos foráneos que se sumaban a los mudéjares locales que perdían su libertad ${ }^{12}$.

\section{LOS ESCLAVOS SARRACENOS EN VALENCIA, 1409-1425}

Las siguientes páginas, que constituy en el núcleo principal del artículo, son el resultado de nuestra propia investigación, un estudio sobre la esclavitud sarracena a inicios del siglo XV que se enmarca en un proyecto de análisis global de la esclavitud en Valencia entre los siglos

11. Ch. Verlinden, L'esclavage..., vol. I, cit., pp. 419-426; M. T. FerRer I MALlol, Els sarraïns de la Corona catalano-aragonesa en el segle XIV. Segregació i discriminació, Barcelona, 1987, pp. 18-28, pp. 106-109, pp. 111-118 y pp. 193-198; ÍDEM, La frontera amb l’Islam en el segle XIV. Cristians i sarraïns al País Valencià, Barcelona, 1988, pp. 10-15; J. Hinojosa MonTAlvo, “La esclavitud en Alicante...”, cit., pp. 376-377 y pp. 384-385; F. GARCIA-OLIVER, Cistercencs del País Valencià. El monestir de Valldigna (1298-1530), Valencia, 1998, pp. 101-106; M. RuzAfa GARCíA, “La esclavitud en la Valencia bajomedieval: mudéjares y musulmanes”, en M. T. Ferrer I MALlol - J. Mutgé I Vives (Eds.), De l'esclavitud a la llibertat. Esclaus i lliberts a l'Edat Mitjana, Barcelona, 2000, pp. 471-491.

12. V. CoRtés Alonso, La esclavitud en Valencia durante el reinado de los Reyes Católicos (1479-1516), Valencia, 1964, especialmente pp. 27-53; J. Hinojosa MonTAlvo, “La esclavitud en Alicante...”, cit. Para la esclavitud en los primeros siglos modernos, en los que el componente sarraceno sigue siendo fundamental, V. GraUlLERA SANZ, La esclavitud en Valencia en los siglos XVI y XVII, Valencia, 1978. 
$\mathrm{XIV}$ y $\mathrm{XV}^{13}$. Lo que aquí p resentamos son las conclusiones de esa investigación, las ideas generales, unas ideas generales que, debe quedar claro, sólo pretendemos válidas para el período objeto de estudio. Posiblemente, muchas puedan extrap olarse a otras cronologías, pero mientras no se estudien en profundidad esas otras cronologías ni se podrá afirmar su validez ni se podrá tener una imagen global de la esclavitud sarracena en Valencia, de la presencia de unos esclavos que, no lo olvidemos, no dejan de ser musulmanes en territorio cristiano, si bien en un territorio cristiano con una imp ortante comunidad musulmana autóctona, hecho éste también muy a tener en cuenta. La documentación que hemos empleado procede del Archivo del Reino de Valencia, siendo especialmente imp ortante la emanada de la Bailía General (hoy en día contenida en las Secciones de Bailía, Maestre Racional y, algunos volúmenes, Real Cancillería), si bien hemos utilizado igualmente documentación notarial ${ }^{14}$. Con respecto a la bibliografía, y partiendo del hecho de que son numerosas las lagunas de conocimiento, tanto en cronología como en temática,

13. F. J. Marzal Palacios, Los esclavos sarracenos en Valencia a inicios del siglo XV (1409-1425), Facultat de Geografia i Història de la Universitat de Valèn cia, Tesis de Licenciatura inédita, 1999, dirigida por Manuel Ruzafa García. Nuestro proyecto de investigación, dirigido por Paulino Iradiel Murugarren y por Manuel Ruzafa García, lleva por título «La esclavitud en Valencia durante la baja Edad Media (1375-1425)». Algunos resultados, parciales, de ese estudio de la esclavitud sarracena entre 1409 y 1425 ya han sido publicados: “La frontera valenciana y la esclavitud: aspectos económicos (1409-1425)”, en F. Toro Ceballos - J. Rodríguez Molina (Coords.), II Estudios de Frontera. Actividad y vida en la frontera, Jaén, 1998, pp. 553-563; “Solidaridad islámica, negocio cristiano: la liberación de esclavos musulmanes por mudéjares en la Valencia de inicios del Cuatrocientos”, en G. CIPOLLONE (a cura di), $L a$ liberazione dei 'captivi' tra Cristianità e Islam. Oltre la crociata e il gihad: tolleranza e servizio umanitario, Ciudad del Vaticano, 2000, pp. 777-787; “El ciclo de la esclavitud sarracena en la Valencia bajomedieval: esclavización, rescate y vuelta a casa de los esclavos de Cherchell (1409-1425)”, en M. T. Ferrer I MALlol - J. Mutgé I Vives (Eds.), De l'esclavitud a la llibertat. Esclaus i lliberts a l'Edat Mitjana, Barcelona, 2000, pp. 493-509; “Esclavos nazaríes en Valencia a inicios del siglo XV: un reflejo de la frontera marítima bajomedieval”, en F. ToRo CeBAllos - J. RodRíGuEz Molina (Coords.), III Estudios de Frontera. Convivencia, defensa y comunicación en la frontera, Jaén, 2000, pp. 475-489; “Los esclavos sarracenos entre el Islam y el Cristianismo: el caso de Bernat Sans”, en VIII Simposio Internacional de Mudejarismo. De mudéjares a moriscos: una conversión forzada, Teruel, 2002, vol. 1, pp. 303-314, en colaboración con Ma N. Munsuri Rosado.

14. Las referencias archivísticas de la documentación empleada son las siguientes, todas, recordamos, procedentes del Archivo del Reino de Valencia. De la Sección Bailía las siguientes series: Ápocas, volúmenes 41 a 44; Confesiones de cautivos, volumen 193; Contratos, volúmenes 211 y 212; Lletres $i$ Privilegis, volúmenes 1144 a 1146; y Pleitos, volúmenes 1429 y 1430. De la Sección Maestre Racional las siguientes series: Cuentas Generales de Administración, volúmenes 28 a 45; Bailía de Xàtiva, volúmenes 3016 a 3020; y Bailía de Orihuela-Alicante, volúmenes 4546 a 4551. De la Sección Real Cancillería el volumen 626, Confesiones y ventas de sarracenos; los volúmenes 664, 680 y 702, Armamentos; y el volumen 706, que contiene las licencias de emigración de los sarracenos. De la Sección Fondos Notariales los protocolos y notales de los notarios Vicent Saera, Andreu Puigmitjà y Joan de Campos sr. 
que tenemos acerca de la esclavitud sarracena en Valencia, las décadas iniciales del siglo XV son las que cuentan con más estudios a este respecto, unos estudios realizados a partir de esa documentación procedente de la Bailía General, que muestra la llegada de los esclavos y su inserción, a través del mercado, en la realidad valenciana, siendo José Hinojosa el autor más prolífico en este sentido, con trabajos que podemos considerar ya clásicos en el estudio de la esclavitud valenciana bajomedieval ${ }^{15}$.

Antes de entrar en materia, conviene hacer dos precisiones. La primera se refiere a lo que nosotros entendemos por esclavos sarracenos. Bajo este término agrupamos tanto a esclavos locales como a esclavos foráneos. Los primeros son los mudéjares valencianos que p or diferentes motivos han perdido su libertad, mientras que los segundos proceden de los diferentes sultanatos norteafricanos, así como del de Granada. En este segundo grupo también hemos incluido, porque la documentación los califica de sarracenos, a esclavos que casi con total seguridad proceden del sur del Sahara, negros llevados hasta el norte de África tras atravesar ese desierto, islamizados en mayor o menor medida, por lo general escasamente, y que con posterioridad son conducidos hasta territorio valenciano. Somos conscientes de lo problemático que puede resultar esa inclusión, pero no es posible para inicios del siglo XV realizar segregación alguna, al menos basada en parámetros objetivos, cuando la documentación, sobre todo la notarial, identifica de la misma forma, bajo el término sarraceno, a esclavos norteafricanos y granadinos y a determinados, no siemp re es así, esclavos subsaharianos. La segunda precisión se refiere al hecho de que los esclavos sarracenos no eran los únicos que estaban presentes en la Valencia del primer cuarto del siglo XV. Junto a ellos, y en gran cantidad, se encontraban esclavos orientales, básicamente y por grado de importancia numérica tártaros, rusos y circasianos, así como también, aunque en bastante menor número, esclavos balcánicos, sobre todo búlgaros, y sardos. Todos componían un grupo esclavo valenciano que a grandes rasgos se caracterizaba, en cuanto a su procedencia, por lo mismo que en otras ciudades del occidente mediterráneo cristiano, la diversidad, como ya señalamos en su momento.

\section{1- EL APROVISIONAMIENTO DE ESCLAVOS SARRACENOS}

Partiendo del hecho de que es imposible conocer de forma exacta cuántos esclavos sarracenos llegaron hasta Valencia entre 1409 y 1425, y que por lo tanto las cifras que nosotros vamos a ofrecer sólo deben ser entendidas como un mínimo, aunque, eso sí, exp onentes de unas tendencias, lo que resulta evidente es el predominio de la violencia sobre la trata en cuanto a

15. J. Hinojosa Montalvo, “Confesiones y ventas...”, cit.; ÍDE M, “Tácticas de apresamiento...”, cit. Este autor también ofrece una visión de conjunto de la esclavitud bajomedieval valenciana en "De la esclavitud a la libertad en el reino de Valencia durante los siglos medievales”, en M. T. Ferrer I MALlol - J. MutgÉ I Vives (Eds.), De l'esclavitud a la llibertat. Esclaus i lliberts a l'Edat Mitjana, Barcelona, 2000, p p. 431-470. 
medio de suministro de este tipo de esclavos. De igual forma, son gentes procedentes del propio reino de Valencia las que se van a encargar de traer a la may or parte de esos esclavos sarracenos. Ambas circunstancias, tipo de suministro y origen de los suministradores, diferencian la llegada de esclavos sarracenos de la de otros colectivos esclavos, caso de los orientales o balcánicos. De los 899 esclavos sarracenos que llegaron a la ciudad de Valencia en esos años, 603, es decir el $67 \%$, lo hicieron a través de las actividades violentas, frente a 237, poco más de un $26 \%$, que lo hicieron a través de la actividad comercial, de la trata, siendo 59, algo más del 6\%, los esclavos de los que no podemos afirmar cómo llegaron hasta Valencia. Desde el punto de vista geográfico, de esos 899 esclavos 654, casi el 73\%, fueron conducidos hasta la ciudad de Valencia por gentes del propio reino, 51, el 5,6\%, por gentes del resto de la Corona de Aragón, 50, el 5,5\%, por castellanos, y 13, el 1,5\%, por gentes del resto de Europa, mientras que son 131, el 14,6\%, los esclavos de los que desconocemos quién los introdujo en la capital valenciana. Por lo que respecta a la zona de Orihuela-Alicante, el otro gran espacio de entrada de esclavos sarracenos del reino de Valencia, lo que se observa es una acentuación de las tendencias antes expresadas, puesto que la práctica totalidad de los esclavos que llegan lo hacen a través de la violencia y de la mano de gentes no ya del conjunto del reino de Valencia, sino del propio territorio alicantino.

En el suministro a través de la violencia, y lo que entendemos por tal es el conjunto de esclavos llegados de la mano de las personas que ejercieron esa violencia, el protagonismo, casi de forma absoluta, recae en la violencia marítima, en la violencia ejercida en el mar o desde el mar, frente a la violencia terrestre. Así, se puede afirmar que la frontera con Granada ha dejado, por lo que se refiere al suministro de esclavos sarracenos a la ciudad de Valencia, de representar un elemento importante. Son muy pocos los esclavos que llegan por esta vía, cifras inapreciables si las comparamos con la afluencia de esclavos procedentes de la actividad marítima. De esos 603 esclavos señalados anteriormente como llegados a través de las actividades violentas, 595 lo hicieron de la mano de corsarios y hombres de mar. Si recordamos que fueron 899 los esclavos sarracenos que llegaron hasta la ciudad de Valencia, queda claro que el protagonismo en el abastecimiento lo ejerce el grupo de hombres de mar, en especial corsarios, y a que ellos son los encargados de traer hasta Valencia ap roximadamente a dos de cada tres esclavos sarracenos que llegan hasta la capital.

Son suficientemente conocidos, gracias a los trabajos de José Hinojosa, los comportamientos corsarios, sus tácticas o las zonas donde éstos actuaban, por lo que no nos detendremos sobre estas cuestiones. Preferimos centrarnos en otros aspectos, como son el origen de esos hombres de mar que traen hasta la ciudad de Valencia sus esclavos, la llegada de esclavos de Cherchell en 1412 y, por último, la relación entre diplomacia y suministro a través de la violencia. Sobre la primera cuestión, se aprecia un predominio notorio de los hombres de mar valencianos como introductores de esclavos frente a otros orígenes, fundamentalmente 
castellanos y baleáricos, unos hombres de mar valencianos que proceden tanto de la capital como del sur del reino, en especial la ciudad de Alicante. Son precisamente los corsarios de Alicante los que se van a constituir en pieza clave en el suministro de esclavos sarracenos a la ciudad de Valencia, en una cronología centrada, sobre todo, en los años 1420 a 1425, cuando van a colocar en el mercado valenciano un mínimo de 124 esclavos. Por lo que hace referencia a la llegada de esclavos de Cherchell, aunque la documentación valenciana no se haga eco de la misma, no al menos en la medida de su importancia, sabemos que en 1412 Rodrigo de Luna, sobrino de Benedicto XIII, asaltó esa localidad del litoral norteafricano, situada al oeste de Argel, haciéndose con un botín humano de varios centenares de personas, en su mayoría mujeres y niños, conducidos con posterioridad hasta Peñíscola, distribuyéndose una cantidad imposible de conocer, pero seguramente importante, por el reino de Valencia. Respecto a la última cuestión, se puede afirmar que la actividad dip lomática influyó de una manera destacada en la llegada de esclavos sarracenos a Valencia. Siendo como era que la may oría de estos esclavos llegaban hasta Valencia como consecuencia de acciones violent as ejercidas sobre ellos, es lógico pensar que la limitación de la posibilidad de ejercer esa violencia, mediante acuerdos de tregua con los diferentes sultanatos musulmanes, limitase de igual forma la llegada de es clavos sarracenos a Valencia. Así era. El período de menor llegada de esclavos sarracenos se corresponde perfectamente con el período de treguas entre Aragón, por una parte, y Granada y Fez, por otra. Se coartaba la capacidad de intervención de los corsarios, y se hacía precisamente allí donde mayores posibilidades se tenía de ejercer esa caza del hombre que era la esclavización de sarracenos, las aguas más cercanas al Estrecho de Gibraltar. Evidentemente, continuaron llegando esclavos sarracenos a Valencia, naturales podemos suponer de los sultanatos de Tremecén y Túnez, pero el período de treguas, los años 1413-1417 a grandes rasgos, se caracteriza por un descenso en el número de sarracenos que arribaron hasta Valencia. De la misma forma, cuando la actividad diplomática fue inexistente, en el sentido de no llegarse a acuerdo de tregua alguno, y todas las presas pudieron en princip io declararse legales, desde 1418, el número de esclavos llegados vía corso hasta Valencia aumentó de forma significativa.

Del suministro a través de la trata, lo primero que debe quedar claro es que desde el norte de África o el sultanato de Granada no se importan a Valencia esclavos originarios de esas regiones. La inexistencia de trata entre el norte de África-Granada y el reino de Valencia no implica, sin embargo, que no podamos hablar de la llegada hasta Valencia de esclavos norteafricanos o granadinos p or vía comercial, y ahí están las cifras indicadas anteriormente para certificarlo. Como señalamos al inicio de este trabajo, la presencia de esclavos sarracenos era importante en el espacio delMediterráneo occidental cristiano, y de ahí procederá una buena parte de los 237 esclavos sarracenos que llegaron en el contexto de operaciones comerciales. Hasta la ciudad de Valencia llegan sarracenos desde las islas Baleares, Sicilia y, en menor medida, Cataluña o Castilla. Además, llegaban igualmente, y en cantidad apreciable, esclavos 
desde Alicante, centro corsario bien abastecido que redistribuía una parte de las presas que hasta allí llegaban a la capit al del reino. Acabamos de señalar que no se puede hablar de tráfico de esclavos desde el norte de África hasta Valencia, pero hemos tenido buen cuidado en precisar que se trata de esclavos originarios de esa zona. Y es que, de hecho, sí que existe un comercio de esclavos entre el norte de África y la ciudad de Valencia, aunque referido exclusivamente a sujetos procedentes del sur del Sahara. Es una trata negrera que se practica desde el Magreb Central, con origen en ciudades como Orán, Honein o Alcudia, que afecta tanto a hombres como a mujeres, en la que son protagonistas, como importadores, valencianos tanto de religión cristiana como musulmana, y que, por último, es especialmente significativa en los años centrales de la década de 1410, justo cuando menor es la afluencia de sarracenos norteafricanos y granadinos a consecuencia de las treguas con los diferentes sultanatos. Por lo que se refiere a los protagonistas de la trata, tanto la que tenía su origen en el norte de África como la que procedía de territorios cristianos, si geográficamente casi el 75\% de los esclavos sarracenos que llegaban a Valencia eran introducidos por gentes del propio reino de Valencia, profesionalmente lo que se observa es una diversidad, ya que los mercaderes sólo son responsables de la entrada del 56\% de los esclavos, llegando el resto de la mano de representantes de otras profesiones o condiciones sociales.

Junto a los extranjeros, la comunidad esclava sarracena estaba formada en Valencia por elementos autóctonos, mudéjares que perdían su libertad al cometer algún delito, concep to éste siempre muy amplio, convirtiéndose a todos los efectos en esclavos. Son básicamente tres los delitos que podían conllevar la esclavización de un mudéjar valenciano. En primer lugar los de carácter sexual, que la documentación engloba por lo general bajo el término adulterio. Lo más destacable es que casi todos los mudéjares esclavizados por este motivo eran mujeres, a pesar de que, lógicamente, en acciones de este tipo intervenían personas de ambos sexos. En segundo lugar los delitos que podemos calificar como crímenes comunes, que se refieren a comportamientos tales como el robo, la violencia doméstica o el asesinato. En este caso, los mudéjares que perdían la libertad por su comisión eran en su may or parte de sexo masculino. En tercer y último lugar la emigración ilegal. En este delito la fecha clave es 1418, cuando por orden de Alfonso V se prohibió que los mudéjares pasasen sin licencia real más allá de la línea Biar-Xixona, zona conocida como Vall d'Elda, con lo que ya ni siquiera se trataba de una emigración exterior, puesto que los movimientos en el interior del propio reino podían conllevar la esclavización. Es a partir de esa fecha cuando los casos de mudéjares esclavizados por emigración ilegal se multiplican. Para concluir con la cuestión de la esclavización de mudéjares, sólo formular algunas precisiones. En primer lugar, que la comisión de un delito, de cualquier tipo de delito de los anteriormente señalados, no implica de forma automática la esclavización. Son numerosos los casos de mudéjares que han cometido adulterio, que han robado o que han sido sorprendidos emigrando ilegalmente que sólo son condenados a pagar una determinada 
cantidad de dinero. En segundo lugar, son también frecuentes los casos de liberaciones inmediatas, es decir, de mudéjares esclavizados que antes de ser vendidos a un particular consiguen rescatarse o ser rescatados. De ambas circunstancias podemos extraer la conclusión de que en el reino de Valencia no se fuerza, en ningún caso y siempre hablando en términos generales, la máquina de la esclavización mudéjar. En tercer y último lugar debemos tener claro que los delitos a los que nos hemos referido tienen un carácter distinto, y de igual modo son juzgados según un procedimiento distinto. Mientras que el adulterio, el robo o la violencia tienen un componente religioso, y se juzgan según la ley islámica, condenándose al culpable a determinadas penas físicas, azotes o amputación, de las que el implicado puede librarse entregándose como esclavo al rey o a su señor, dependiendo de quien posea la máxima jurisdicción sobre él, la emigración ilegal tiene un componente político, se juzga exclusivamente por oficiales reales y en caso de decidirse por aplicar la máxima pena ésta consiste en la esclavización, y no en castigos físicos, de la que el mudéjar puede librarse con posterioridad, como hemos señalado, mediante el pago de una composición económica a las arcas reales.

\section{2- LA CARACTERIZACIÓN DEL GRUPO}

La rica documentación valenciana permite conocer diversas características del colectivo esclavo sarraceno. Nosotros vamos a centrar nuestra atención en tres, como son el sexo, la edad y el origen geográfico de esos esclavos sarracenos presentes en Valencia en los primeros años del siglo XV.

En cuanto al sexo, se puede afirmar que el grup o esclavo sarraceno está compuesto may oritariamentep or hombres, aunque resulta un tanto más comp licado determinar elporcentaje en el que se concreta esa superioridad. Siguiendo los Libros de Confesiones de Cautivos esa proporción es abrumadora a favor de los varones, ya que de 306 esclavos de los que conocemos su sexo a través de esta fuente, sólo 12 , el $4 \%$, son mujeres. Sin embargo, observando el sexo de los esclavos sarracenos que una vez liberados salen del reino entre 1409 y 1425, a través de las rúbricas de Delmaments contenidas en los Libros de Cuentas Generales de Administración, la proporción varía de forma significativa, ya que de los 307 antiguos esclavos que abandonaron Valencia en esas fechas, 84 , lo que supone un $27 \%$, son mujeres. Un porcentaje similar al que se aprecia estudiando las licencias de emigración entre julio de 1421 y 1425, documentación con may or grado de detalle que la contenida en las rúbricas de Delmaments, puesto que de 157 esclavos y a liberados que salieron de Valencia en esas fechas, 41, un 26\%, eran mujeres. En uno y otro caso conviene precisar que las antiguas esclavas que abandonaron el reino procedían en su may or parte de Cherchell, localidad norteafricana que como ya señalamos fue asaltada en 1412 y donde se esclavizó de forma preferente a mujeres y niños. Por último, si recogemos los datos que nos suministran las actas de compraventa de esclavos sarracenos contenidas en los protocolos notariales, nos encontramos con que de 222 actos de este tipo, 71, un 32\%, se refieren 
a mujeres, aunque, eso sí, de muchas de esas mujeres podemos sospechar su origen subsahariano, colectivo caracterizado por un relativo equilibrio entre sexos, y no estrictamente norteafricano o granadino.

Por lo que hace referencia a la edad, a partir de las actas de compraventa de esclavos sarracenos de las que tenemos noticia, y en las que, lógicamente, este dato viene indicado, lo que no sucede siempre, un total de 517, 427 que afectan a hombres y 90 a mujeres, la edad media del conjunto de estos esclavos se sitúa en algo más de 25 años, siendo las mujeres más jóvenes, 21 años de promedio, que los hombres, algo más de 26 años. Como ocurría cuando hablábamos del sexo, debemos tener en cuenta dos situaciones que influyen en esa determinación del promedio de edad de los sarracenos, como son por un lado la presencia de esclavos de Cherchell, muchos de ellos niños, y por otro la certeza de que una parte de esos esclavos sarracenos, sobre todo los negros, en realidad son sujetos procedentes de la trata sahariana, esclavos que si en materia de sexo se caracterizaban por un equilibrio, en cuestión de edad se caracterizan por su juventud. En definitiva, tanto la llegada de esclavos de Cherchell como la presencia de esclavos subsaharianos tiende a feminizar y rejuvenecer el colectivo esclavo sarraceno presente en Valencia entre 1409 y 1425.

Con respecto al origen geográfico, son varias las ideas a destacar. En primer lugar, y siempre referido a los esclavos foráneos cuyo origen conocemos, se aprecia una clara superioridad de los norteafricanos frente a los granadinos, en una proporción aproximada del 80-20. En segundo lugar, la importancia de la proximidad geográfica en la mayor o menor p resencia de esclavos de un determinado origen, y así, a más proximidad más presencia. La may oría de los esclavos sarracenos de origen conocido procede del sultanato de Fez, después de los de Tremecén y Granada y, en último término, del de Túnez. La actividad marítima, corsaria, al incidir sobre unas determinadas aguas y costas, las más próximas a territorio valenciano, con el horizonte del Estrecho de Gibraltar siempre al fondo, tiene mucho que ver en esa distribución. En tercer lugar, una circunstancia que siempre hay que tener presente, como es el hecho de que junto a esos esclavos sarracenos foráneos nos encontramos en Valencia con una numerosa colonia de esclavos autóctonos, mudéjares esclavizados que a pesar de que su cuantificación es muy dificultosa no dejan de tener su importancia numérica en el conjunto de los esclavos sarracenos. Por último, es necesario señalar que nos encontramos circulando por el mercado valenciano a un relativamente numeroso grup o de esclavos negros, calificados de sarracenos, de los que nada se indica sobre su origen, esclavos que nosotros creemos en su may or parte naturales del África subsahariana.

\section{3- EL MERCADO DE ESCLAVOS SARRACENOS}

Nos encontramos sin duda ante la cuestión más compleja de analizar, y no tanto porque presente una dificultad intrínseca, sino porque al hablar de mercado de esclavos sarracenos 
estamos hablando de algo que no existe. Lo que existe es el mercado de esclavos como tal, en el que se incluyen todos los seres privados de libertad, de cualquier origen, que se encuentran en Valencia en una cronología concreta. Realizar divisiones según la procedencia de los esclavos sup one introducir un factor de artificialidad en el análisis, desvirtuarlo en cierta forma. Nosotros somos conscientes de este hecho, y porconsiguiente lo que aquí pretendemos no es tanto mostrar una visión global del mercado como incidir en dos aspectos muy concretos del mismo, el trabajo esclavo y la función redistribuidora de la ciudad de Valencia.

Todos los esclavos sarracenos que llegaron a Valencia entre 1409 y 1425 estaban destinados al desempeño de alguna actividad laboral. Para intentar conocer esa actividad vamos a recurrir a un medio imperfecto, sobre el que se podrían formular numerosas objeciones pero que por lo general es el único existente, como es el de ver quién adquiría esos esclavos sarracenos. Como hemos señalado anteriormente, el grup o esclavo sarraceno estaba compuesto en su may or parte por hombres, por lo que no es de extrañar que muchos de ellos, la may oría, fuesen adquiridos por artesanos. Son miembros de numerosos oficios diferentes los que se hacen con la propiedad de algún esclavo sarraceno, pero sin duda entre esos oficios destaca el de carpintero y el de panadero-hornero. Por su parte, dentro del sector terciario destacan sobremanera las adquisiciones de esclavos sarracenos realizadas por mercaderes, que los deberían dedicar a tareas de tipo muy diverso. Del sector primario es necesario señalar que los agricultores valencianos, de la capital o de su entorno más inmediato, cuando acudían al mercado para hacerse con este tipo de esclavos lo que adquirían casi siempre eran varones negros jóvenes, sin duda procedentes de la trata sahariana, que podemos entender se ajustaban mejor a sus necesidades. En definitiva, en ese gran trasvase de mano de obra que entre otras cosas significaba la esclavitud, en Valencia nos encontramos con un doble proceso. Si por un lado tenemos todo ese conjunto de esclavos sarracenos foráneos que son conducidos hasta el reino de Valencia, en especial hasta su capital, para trabajar, dentro del propio reino, con los esclavos mudéjares, también se puede señalar un fenómeno similar, ya que muchos de esos mudéjares valencianos que pierden su libertad, mudéjares procedentes de núcleos alejados en may or o menor medida de la ciudad de Valencia, van a ser adquiridos por gentes de la capital, siendo obligados a prestar allí servicios laborales, lo que de otro modo casi con toda seguridad nunca habría ocurrido.

En cuanto a la función redistribuidora de la ciudad de Valencia, siempre por lo que se refiere a los esclavos sarracenos, ésta se circunscribe a su entorno geográfico más inmediato, las islas Baleares, Cataluña y la Corona de Castilla, en unas líneas de trata que, por lo menos para los dos p rimeros territorios, muy posiblemente estaban ya activas en fechas anteriores a 1409. El balear era el espacio hacia el que el tráfico de esclavos desde Valencia se mostraba más activo y constante. Desde la capital valenciana los esclavos, por lo general naturales del norte de África o Granada, no subsaharianos, varones y de edades intermedias, partían con destino tanto a Mallorca como a Ibiza, ya fuese por iniciativa de mercaderes y otras 
gentes de las islas, que en ocasiones se hacían con la mercancía adquiriéndola a los corsarios, sin dar tiempo por lo tanto a que ésta circulase por Valencia, ya fuese por iniciativa de valencianos, quienes se desplazaban hasta esos mercados para colocar allí sus esclavos. La segunda gran zona hacia la que partían esclavos sarracenos era Cataluña, en especial su capital. Son esclavos tanto blancos como mulatos, tanto norteafricanos como granadinos, pero también, a diferencia de lo que señalábamos para el caso balear, negros. El tráfico con destino a Cataluña es especialmente significativo en la década de 1420, y en él intervenían tanto catalanes, en su gran may oría mercaderes, que compraban en Valencia esos esclavos, como valencianos, que se desplazaban hasta Cataluña. Por último, en la trata hacia el espacio castellano, sobre todo hacia Andalucía y dentro de ésta a su capital, Sevilla, las cuestiones más relevantes son la no intervención de valencianos en ese tráfico, frente a lo que ocurría en la trata con dirección a las islas Baleares y Cataluña; el amplio espectro social de los compradores castellanos, en el que destacan los nobles; la concentración de esas adquisiciones en la década de 1410; y la predilección por un tip o de esclavo muy concreto, mujeres negras de edades variables, desde casi niñas a adultas, esclavas que podemos catalogar, al menos en buena parte, como subsaharianas, una predilección p or este tipo de esclavas que nos muestra un componente de la demanda sevillana, y en general castellana, demanda que, al contrario de lo que sucedería con los esclavos blancos, cuyo ap rovisionamiento, vía frontera, debería ser regular, sería resp ondida mediante la adquisición en mercados exteriores, como el valenciano, y su posterior importación. Estamos ante un tráfico modesto pero digno de ser tenido en cuenta, tráfico que por otro lado preludia, aunque se desarrolle en sentido contrario, la gran trata de negros que desde finales del siglo XV va a tener lugar entre el espacio castellano y el reino de Valencia.

\section{4- LAS DIFERENTES VÍAS HACIA LA LIBERTAD}

De la misma forma que vemos llegar a los esclavos sarracenos, de la misma forma que los vemos circular p or el mercado, los vemos recuperar su libertad y volver, en muchas ocasiones, a su tierra. Los medios para alcanzar la tan deseada libertad son muy variados, pero nosotros nos vamos a centrar únicamente en tres, dos legales (y exclusivamente sarracenos), como son el rescate por mudéjares y el intercambio p or cristianos esclavos en territorio musulmán, y uno ilegal (al que recurrían esclavos de cualquier origen), como es la fuga. Lo hacemos p orque son los medios sobre los que disp onemos de may or información, pero somos conscientes de que posiblemente la may oría de los esclavos sarracenos conseguía recuperar su libertad recurriendo a otras fórmulas, ya fuese la ayuda económica desde su tierra, pagando el rescate exigido con el producto de su trabajo, mediante un acuerdo con el propietario para servir una determinada cantidad de años, a través de una disposición testamentaria o, simplemente, beneficiándose de una manumisión graciosa concedida por el propietario.

Por lo que hace referencia a los rescates por mudéjares, éste era un medio de liberación 
del que se beneficiaban principalmente mujeres, niños y varones adultos con una cierta edad, siempre de origen norteafricano y granadino, quedando al margen de esa acción solidaria, lo que es un hecho indicativo, los esclavos negros subsaharianos, sarracenos en la documentación pero no en la mentalidad mudéjar. Son estos colectivos los que se presentan como objeto preferente de la solidaridad mudéjar, por lo que no es de extrañar que en los años centrales de la década de 1410 se desp legase una intensa actividad redencionista, relacionada con la llegada de mujeres y niños de Cherchell. En relación con este tema, es preciso señalar que los musulmanes valencianos no sólo rescataban a sarracenos extranjeros, sino que en ocasiones también hacían lo propio con mudéjares que por un motivo u otro habían perdido su libertad. Aunque la casuística es variada, una buena parte de los rescates se ajustaba a un mismo patrón. Se trata de compras por mudéjares de esclavos sarracenos a sus propietarios cristianos, pero compras efectuadas a crédito, puesto que el precio, por lo general muy elevado, fuera de mercado, se deja a deber, y así, en un documento posterior, se reconoce la deuda y se detallan los plazos de pago, al igual que las penalizaciones por el incumplimiento de los mismos. Es en esos actos de reconocimiento de deuda, y sobre todo en el momento en el que los ant iguos propietarios cristianos se encuentran con problemas p ara cobrar, recurriendo a la justicia, cuando podemos apreciar la gran cantidad de mudéjares valencianos implicados en cada una de esas redenciones, mudéjares de diferentes aljamas y que en ningún caso desempeñan la misma función. Mientras unos aparecen como compradores o garantes del pago, y por lo tanto están expuestos a la actuación de la justicia ante cualquier contratiempo, el nivel de compromiso de la may oría de los musulmanes valencianos que interviene en una operación de este tip o se limita a la promesa de entrega de alguna cantidad, por lo general modesta, para contribuir en el rescate. Por último, en ese complejo y por lo general largo de finiquitar proceso de redención, el antiguo esclavo también tiene un protagonismo activo en la recaudación del monto del rescate, ya que buena parte de su tiempo lo dedica a recorrer diferentes morerías del reino solicitando limosna.

En cuanto a los intercambios de esclavos sarracenos por cristianos, por valencianos esclavizados en territorio musulmán, intercambios todos en el marco de acuerdos privados entre las partes, quepodemos sup oner complejos, sólo son posibles de conocer con detalle desde 1421, fecha a partir de la cual se conservan las licencias de emigración de sarracenos. De esos intercambios el elemento sin duda más destacable es el carácter "granadino” que poseen. Todas las operaciones de intercambio se refieren al sultanato de Granada, no encontrándose mención alguna entre 1421 y 1425, en base a esas licencias de emigración, rep etimos, a intercambios con el norte de África. Además, los sarracenos objeto de intercambio eran prácticamente todos súbditos nazaríes, por lo general naturales de Almería o zonas próximas, y era allí precisamente, lo que en modo alguno puede ser entendido como casual, donde se encontraba la may or parte de los cristianos a intercambiar. La proximidad geográfica del esclavo a su lugar de origen se presenta así como un elemento decisivo a la hora de concluir con éxito una operación de este 
tipo.

Por último, las fugas, fenómeno que alcanzaba en el reino de Valencia unas connotaciones especiales, tanto por el número de esclavos sarracenos presentes como, sobre todo, por la proximidad, marítima y terrestre, a las zonas de origen de muchos de esos esclavos, así como por la presencia en suelo valenciano de una numerosa comunidad mudéjar que, en último término, no dudaba en propiciar la fuga o en prestar ayuda a los sarracenos que la intentaban. Los aspectos más destacados de esas fugas son su carácter masculino, pues todos los casos que hemos manejado nos hablan de fugas protagonizadas por hombres, algo que por otro lado es una constante en la historia del esclavismo bajomedieval europeo; su componente en ocasiones “masivo”, con dos o tres esclavos, del mismo prop ietario o no, que emprenden juntos la huida; el relativamente escaso número de esclavos sarracenos propiedad de artesanos que se fugan, teniendo en cuenta que este colectivo era el propietario de una buena parte de los mismos; y, para concluir, unas direcciones de fuga, en su ámbito terrestre, centradas en el oeste y sobre todo, no podía ser de otro modo, en el sur, intentando alcanzar el sultanato de Granada, territorio seguro y espacio, para ellos, de libertad.

\section{RESUMEN}

El presente artículo estudia la esclavitud musulmana en la baja Edad Media desde una triple perspectiva. En primer lugar se repasa la presencia, más o menos numerosa, de estos esclavos en las principales ciudades del Mediterráneo occidental cristiano. En segundo lugar, centrándonos ya en Valencia, señalamos la importancia de este colectivo en la esclavitud valenciana de los siglos XIII al XVI. En tercer y último lugar pretendemos mostrar las principales características de la esclavitud musulmana en Valencia en un breve período cronológico, 1409-1425, señalando sus formas de llegada, los rasgos definitorios del grupo, el mercado de esclavos y los caminos hacia la libertad.

Palabras clave: Esclavitud, Baja Edad Media, Valencia, Relaciones Islam-Cristiandad, Movimientos de población forzados, Solidaridad islámica.

\section{ABSTRACT}

It is the goal of this article to present Muslim slavery in Later Middle Ages from three points of view. Firstly, it ponders on the presence, more or less numerous, of Muslim slaves in the main West Mediterranean Christian towns. Secondly, it indicates the importance of this collective in Valencian slavery from thirteenth to sixteenth centuries. Finally, it shows the main characteristics of Valencian Muslim slavery in a short time (1409-1425): way of arriving, defining traits of the group, slave market and distinct ways of emancipation. 
Key words: Slavery, Later Middle Ages, Valencia, Muslim-Christian relationships, Forced movement of population, Muslim solidarity. 